\title{
Mysterious Oddities of Conception-An Insight into Congenital Malformations: A 2 Year Study
}

\author{
${ }^{1}$ Nithya P Jayakumar, ${ }^{2}$ Sharan J Pal
}

\begin{abstract}
Introduction: 'A flower bloomed already wilting. Beginning its life with an early ending'. Some babies with birth defects are unfortunate whose birth is clouded with sadness and worry for the parents because of the birth defects in them which manifest either immediately after birth or after a while, depending on the nature of the congenital abnormality.
\end{abstract}

Aims and objectives: To study the prevalence of fetal anomalies over 2 years in a tertiary care hospital and its relation to maternal and fetal factors.

Materials and methods: A retrospective study from January 2014 to December 2015. Cases with anomalous babies were identified from the birth registry and the corresponding files were retrieved from the hospital medical records section. The details were recorded in the designed proforma and influences of variables such as age, parity, consanguinity,gender, the type of anomalies, mode of termination, associated antenatal complications were studied. Collected data were analyzed by proportions.

Results: Out of 12650 deliveries in 2 years, the overall prevalence of anomalous babies was found to be $0.5 \%$ (63). Incidence of anomalies was found to be more in multipara than primigravida. Among the anomalies detected central nervous system accounted to be the highest $-52.4 \%$, followed by cardiac- $14.3 \%$. Among the various other anomalies facial defects-9.5\%, musculoskeletal-4.8\%, chromosomal-4.8\%, Gastrointestial system$4.8 \%$,abdominal wall defects $-1.6 \%$, genitourinary $-1.6 \%$ and some had combination of one or more systems. Male gender was found to be predominant among the anomalous fetus, $73 \%$ of the mothers had no associated antenatal complications. Two mothers were diagnosed with toxoplasma gondii, other viruses, rubella, cytomegalovirus and herpes simplex (TORCH).

Conclusion: Prevalence of anomalies was found to be $0.5 \%$ over 2 years in our hospital which is comparatively lower than the national average of 2 to $3 \%$ and it was $1.2 \%$ in a study conducted over 5 years (Jan 2008-Dec 2012) in the same hospital settings. Timely antenatal diagnosis of malformations before 20 weeks of pregnancy will provide an opportunity to consult, counsel, intervene and reduce the high morbidity and mortality.

Keywords: Antenatal scan, Congenital anomalies, Prevalence.

\footnotetext{
${ }^{1}$ Senior Resident, ${ }^{2}$ Associate Professor

${ }^{1}$ Department of Reproductive Medicine, CMC Vellore, Tamil Nadu, India

2Department of Obstetrics and Gynecology, KMC Mangaluru, Mangaluru, Karnataka, India

Corresponding Author: Sharan J Pal, Department of Obstetrics and Gynecology, KMC Mangaluru, Mangaluru, Karnataka, India, e-mail: sharanpalin@hotmail.com
}

How to cite this article: Jayaakumar NP, Pal SJ. Mysterious Oddities of Conception-An Insight into Congenital Malformations: A 2 Year Study. J South Asian Feder Obst Gynae 2018;10(3):186-190.

\section{Source of support: Nil}

Conflict of interest: None

Date of received: $12 / 24 / 2016$

Date of acceptance: 01/20/2017

Date of publication: December 2018

\section{INTRODUCTION}

A new life has just begun like any other conception, but its journey and destination is very different and difficult compared to its healthy peers. That's the story of an 'anomalous conception.' Birth defects include abnormalities in the newborn baby's structure, function or body metabolism which usually lead to physical and mental disabilities and can even be fatal sometimes.

Some conceptions may not cross 20 weeks some may suffer intrauterine insults like oligohydramnios or fetal growth restriction, some may end up with preterm labor, in some who may have an apparently normal pregnancy may end up with a catastrophic outcome as sudden intrauterine death (IUD)/ stillbirth or neonatal death.

They vary widely in cause and symptoms. It may be the result of genetic or environmental factors, ${ }^{1}$ maternal infections like rubella, the maternal illness like diabetes and also nutritional deficiencies. ${ }^{2}$ Out of 0.7 million births analyzed in a national study the most common anomaly was neural tube defects (NTD). ${ }^{3}$

Research suggests that paternal food deprivation, germline mutations, alcohol use, chemical mutagens, age, smoking habits and epigenetic alterations can also affect birth outcomes. ${ }^{4-7}$ Prevalence of congenital anomalies is 2 to $3 \%$ in India ${ }^{8}$ and $3 \%$ in USA. ${ }^{9}$ Congenital anomalies account for 8 to $15 \%$ of perinatal deaths and 13 to $16 \%$ of neonatal deaths in India. ${ }^{3,8}$ In the American countries, the type with the greatest numbers of deaths is congenital heart disease $(323,000)$, followed by neural tube defects $(69,000) .{ }^{10}$

\section{AIMS AND OBJECTIVES}

To study the prevalence of fetal anomalies over 2 years in a tertiary care hospital and its relation to maternal and fetal factors. 
Mysterious Oddities of Conception-An Insight into Congenital Malformations - A 2 Year Study

Table 1: Prevalence of anomalies

\begin{tabular}{lll}
\hline Pregnancy with anomalies & $\begin{array}{l}\text { Pregnancy without } \\
\text { anomalies }\end{array}$ \\
\hline $0.50 \%$ & \multicolumn{2}{c}{$99.5 \%$} \\
\hline \multicolumn{3}{l}{ Table 3: Relationship with parity } \\
\hline Parity & Frequency & Percent (\%) \\
\hline Multi & 35 & 55.6 \\
Primi & 28 & 44.4 \\
\hline Total & 63 & 100.0 \\
\hline
\end{tabular}

\section{MATERIALS AND METHODS}

A retrospective study from January 2014 to December 2015. Cases with anomalous babies were identified from the birth registry, and the corresponding files were retrieved from the hospital medical records section.

The details were recorded in the designed proforma and influences of variables such as age, parity, consanguinity, gender, the type of anomalies, mode of termination, associated antenatal complications were studied. Collected data were analyzed by proportions.

\section{RESULTS}

Out of 12650 deliveries in 2 years, the overall prevalence of anomalous babies was found to be $0.5 \%$ (63). Prevalence of anomalies was found to be lower in our hospital than the national average of 2 to $3 \%$ (Table 1 and Fig. 1).

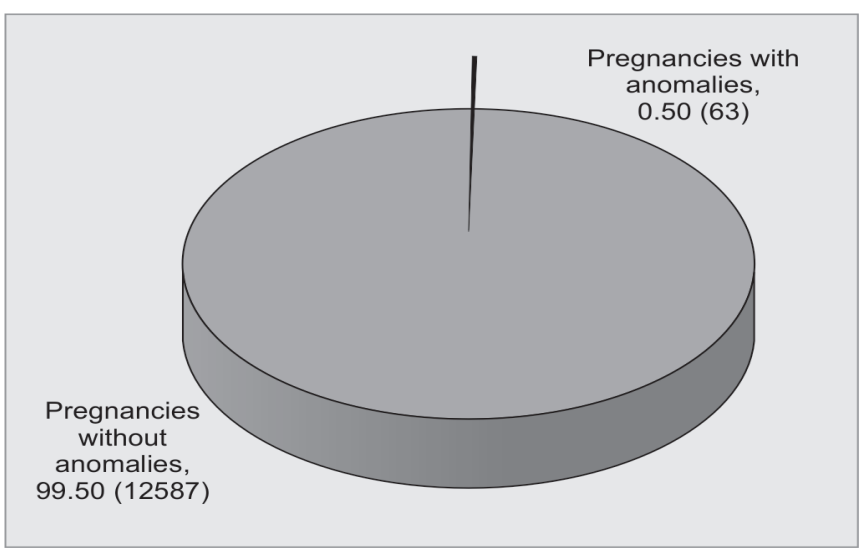

Fig. 1: Prevalence of anomalies

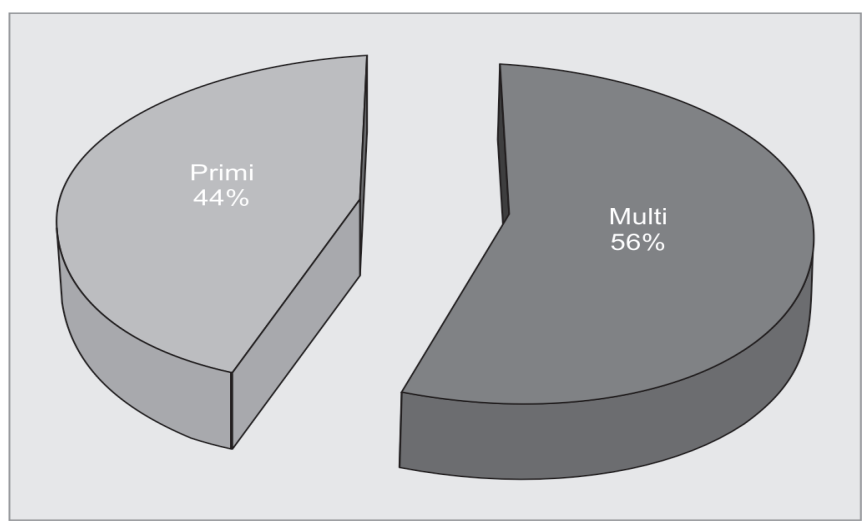

Fig. 3: Distribution of anomalies among primi/multipara

\begin{tabular}{lll} 
& \multicolumn{3}{c}{ Table 2: Relationship with age } \\
\hline$<20$ & Frequency & Percent (\%) \\
$20-34$ & 1 & 1.6 \\
35 and above & 56 & 88.9 \\
Total & 6 & 9.5 \\
\hline \multicolumn{1}{c}{ Table 4: Relationship with gender of the anomalous baby } \\
\hline Gender & Frequency & Percent (\%) \\
\hline Female & 29 & 46 \\
Male & 33 & 52 \\
Indeterminate & 1 & 2 \\
\hline
\end{tabular}

Prevalence was $1.2 \%$ in a study conducted over 5 years (Jan 2008-Dec 2012) in the same hospital settings.

In this study, majority of patients were in the age group of 20-34 years (Table 2 and Fig. 2). Incidence of anomalies was found to be more in multipara than primigravida (Table 3 and Fig. 3). Male gender was found to be predominant among the anomalous fetus (Table 4 and Fig. 4).

Among the anomalies detected central nervous system (CNS) accounted to be the highest- $52.4 \%$, followed by cardiac $-14.3 \%$. Among the various other anomalies facial defects-9.5\%, musculoskeletal-4.8\%, chromosomal-4.8\%, GIT-4.8\%, abdominal wall defects $-1.6 \%$, genitourinary- $1.6 \%$ and some had combination of one or more systems. (Table 5 and Fig 5 ).

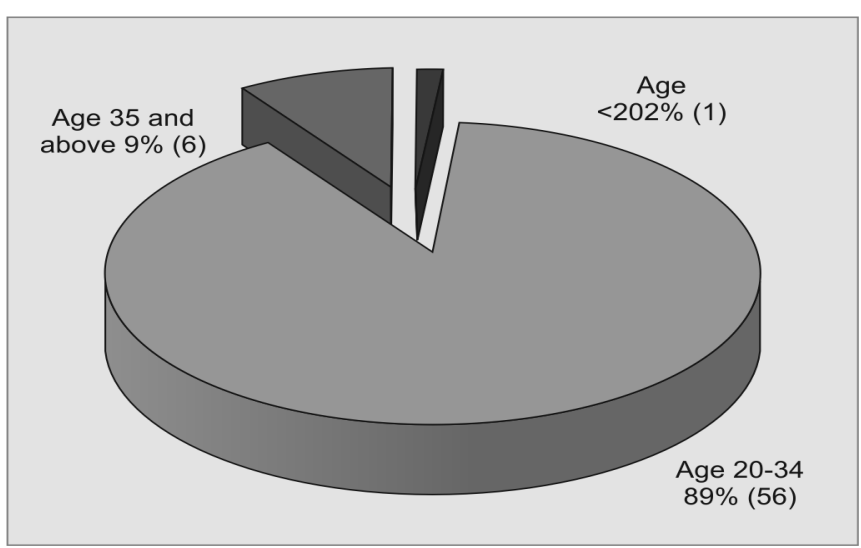

Fig. 2: Distribution of cases with anomalies according to age

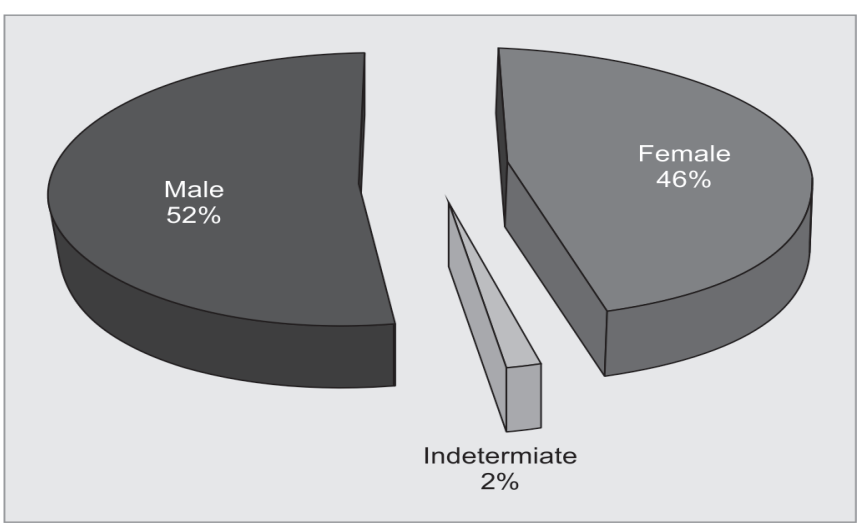

Fig. 4: Relationship with gender of the anomalous baby 
Table 5: Types of anomalies

\begin{tabular}{lll}
\hline & Frequency & Percent (\%) \\
\hline Central nervous system (CNS) & 33 & 52.4 \\
Cardiac & 9 & 14.3 \\
Facial dysmorphism & 6 & 9.5 \\
GIT & 3 & 4.8 \\
Musculoskeletal & 3 & 4.8 \\
Chromosomal & 3 & 4.8 \\
Abdominal wall & 1 & 1.6 \\
Musculoskeletal+GIT & 1 & 1.6 \\
Musculoskeletal+cardiac & 1 & 1.6 \\
Genitourinary & 1 & 1.6 \\
CNS+abdominal wall defects & 1 & 1.6 \\
Abdominal wall & 1 & 1.6 \\
defects+musculoskeletal & & 100.0
\end{tabular}

Table 7: Prevalence of anomalies with consangunity

\begin{tabular}{lll}
\hline & Frequency & Percent (\%) \\
\hline Consanginous & 7 & 11.1 \\
Non-consanginous & 56 & 88.9 \\
\hline Total & 63 & 100.0 \\
\hline
\end{tabular}

Among the studied group $60 \%$ were found to be lethal and 40\% non-lethal (Table 6 and Fig. 6). Consanguinity was seen in $11.1 \%$. (Table 7 and Fig. 7). Booked cases- $-17.5 \%$, booked outside- $49.2 \%$, unbooked-33.3\% (Table 8 and Fig. 8).

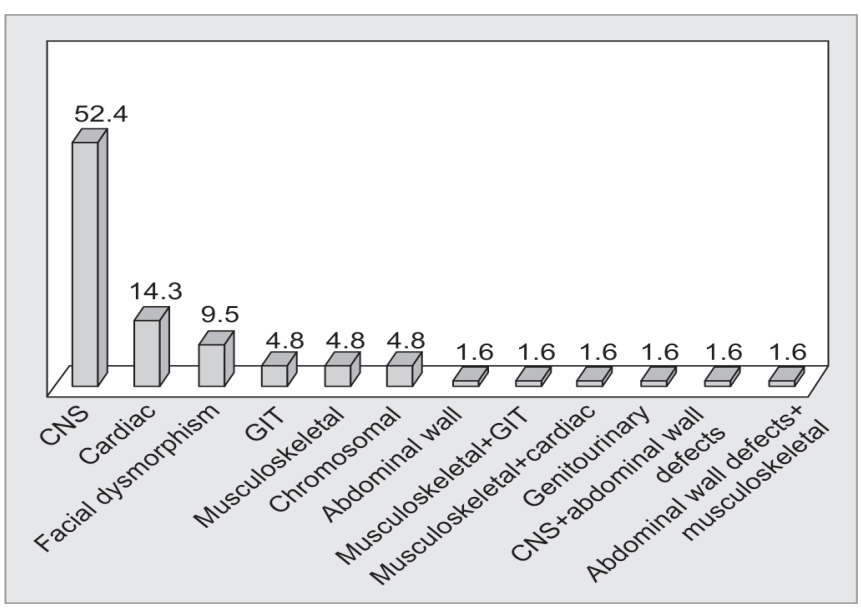

Fig. 5: Types of anomalies

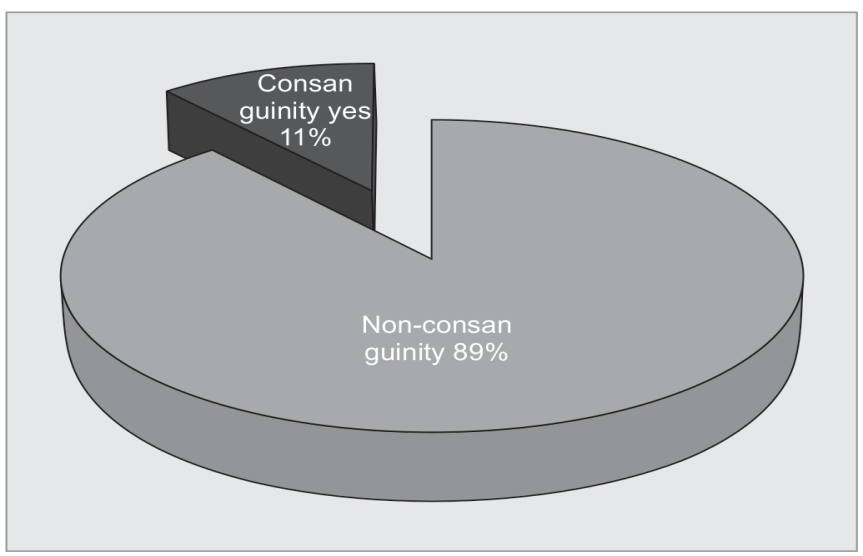

Fig. 7: Prevalence of anomalies with consangunity
Table 6: Lethal/non-lethal anomalies

\begin{tabular}{|c|c|c|}
\hline Lethal anomalies & Non-lethal anomalies & Total \\
\hline $60 \%$ & $40 \%$ & 100 \\
\hline Booked & Frequency & Percent (\%) \\
\hline No & 21 & 33.3 \\
\hline Yes-out & 11 & 17.5 \\
\hline Yes & 31 & 49.2 \\
\hline Total & 63 & 100.0 \\
\hline
\end{tabular}

Table 9: Antenatal complications associated with anomalies

\begin{tabular}{lll}
\hline & Frequency & Percent (\%) \\
\hline Epilepsy & 1 & 1.6 \\
Epilepsy + neurofibromatosis & 1 & 1.6 \\
GDM & 1 & 1.6 \\
HTN + previous LSCS & 1 & 1.6 \\
IUGR & 1 & 1.6 \\
IUGR + Oligo & 1 & 1.6 \\
& 46 & 73.0 \\
Oligo & 2 & 3.2 \\
Overt GDM & 1 & 1.6 \\
PIH & 1 & 1.6 \\
Polyhydramnios & 2 & 3.2 \\
Rh negative & 2 & 3.2 \\
Torch & 2 & 3.2 \\
Twins & 1 & 1.6 \\
\hline Total & 63 & 100.0 \\
\hline
\end{tabular}

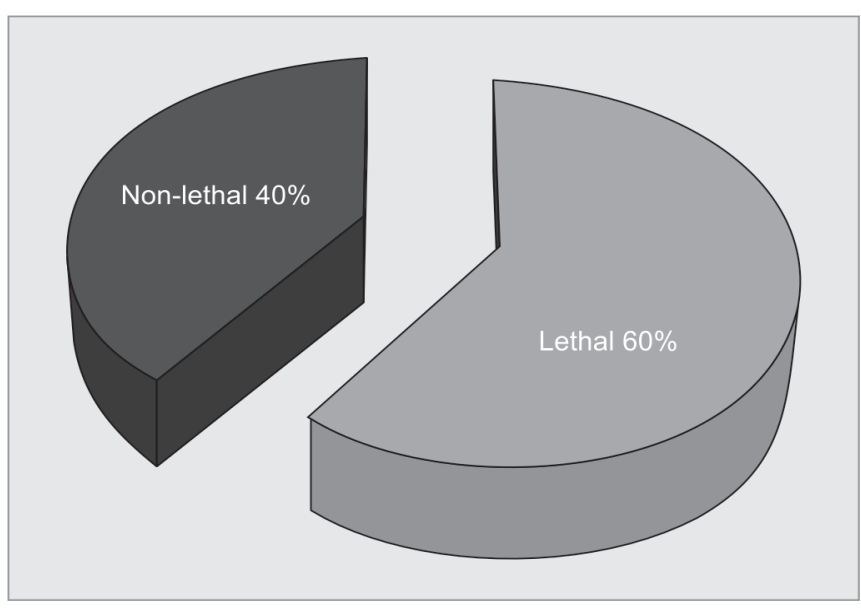

Fig. 6: Lethal/non-lethal anomalies

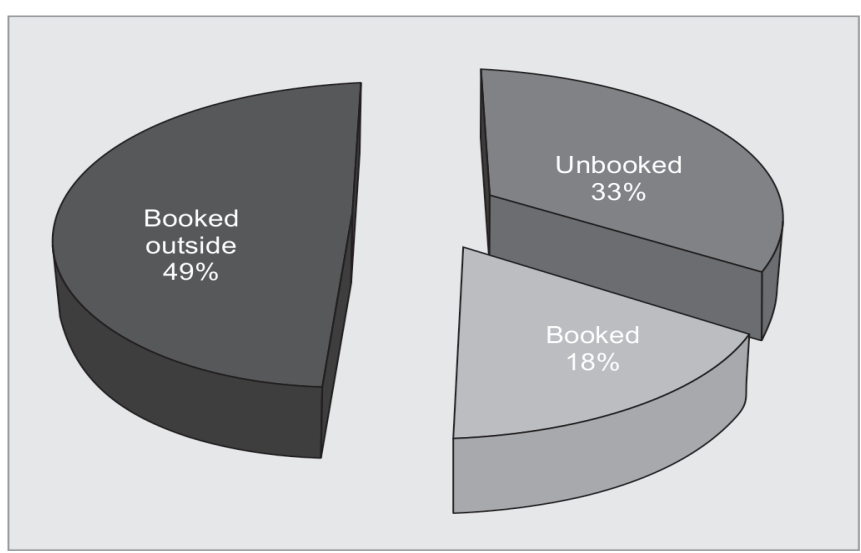

Fig. 8: Relation between booked and unbooked cases 


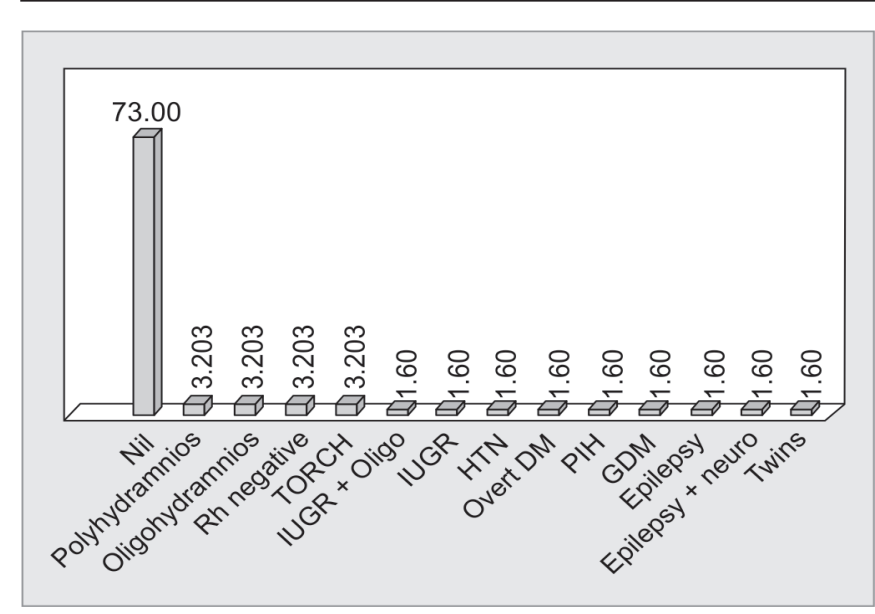

Fig. 9: Antenatal complications asscociated with anomalies

A total of $73 \%$ of the mothers had no associated antenatal complications. Two mothers were diagnosed with TORCH (Table 9 and Fig. 9). The outcome of pregnancies with anomalies were noted as termination by lower segment cesarian section (LSCS) $23.8 \%$, preterm vaginal delivery was $22.2 \%$, full term vaginal delivery was $15.9 \%$ and $36.5 \%$ cases with anomalous fetus were terminated at $<20$ week (Table 10 and Fig. 10). $68.2 \%$ patients had an ultrasound $<20$ weeks, $35.4 \%$ between $20-24 \mathrm{w}$ and $25.85 \%$ had urine specific gravity (USG) $>28$ weeks. Out of 63 cases, 42 had USG $<24 \mathrm{w}$ and in 11 cases who had an FADS, anomaly was missed. Of the missed anomalies 4 were found to be NTD, three cardiac. Others being intracranial anatomical malformations, hydrocephalus, polydactyl and cleft palate.

\section{DISCUSSION}

The incidence of congenital malformations in the study period of 2 years (January 2014 to December 2015) was $0.5 \%$ of 12650 deliveries.

Prevalence of anomalies was found to be lower in our hospital than the national average of 2 to $3 \%$ (Table 1 and Fig 1 ). This could be due to the availability of 6 tertiary
Table 10: Outcome of pregnancies with anomalies

\begin{tabular}{lll}
\hline & Frequency & Percent (\%) \\
\hline $\begin{array}{l}\text { Full-term vaginal delivery } \\
\text { (FTVD) }\end{array}$ & 10 & 15.9 \\
$\begin{array}{l}\text { Lower segment Caesarean } \\
\text { section (LSCS) }\end{array}$ & 15 & 23.8 \\
$\begin{array}{l}\text { Post traumatic vacation } \\
\text { disorder (PTVD) }\end{array}$ & 14 & 22.2 \\
$\begin{array}{l}\text { Terminated } \\
\text { Vaginal birth after Caesar- } \\
\text { ean section (VBAC) }\end{array}$ & 1 & 36.5 \\
\hline \begin{tabular}{l} 
Total \\
\hline
\end{tabular} & 63 & 1.6 \\
\hline
\end{tabular}

health care facilities spread over an area of $132.4 \mathrm{~km}$ in Mangalore. One of the commonly involved systems according to various studies was found to be CNS. In a study conducted by Prasanta Kar et al. in a tertiary care hospital in eastern India the predominant system involved was Musculoskeletal system followed by gastrointestinal (GI) system. Overall incidence of anomalies in our hospital was much lower than 2 to $7 \%$ reported in most studies. ${ }^{11,12}$

Prevalence was $1.2 \%$ in a study conducted over 5 years (Jan 2008-Dec 2012) in the same hospital settings.

In this study, majority of patients were in the age group of 20-34 years (Table 2 and Fig 2). Incidence of anomalies was found to be more in multipara than primigravida (Table 3 and Fig. 3). Male gender was found to be predominant among the anomalous fetus (Table 4 and Fig. 4). Among the anomalies detected CNS accounted to be the highest $-52.4 \%$, followed by cardiac $-14.3 \%$. Among the various other anomalies facial defects $-9.5 \%$, musculoskeletal- $4.8 \%$, chromosomal- $4.8 \%$, GIT- $4.8 \%$, abdominal wall defects- $-1.6 \%$,genitourinary- $1.6 \%$ and some had combination of one or more systems (Table 5 and Fig. 5). Among the studied group 60\% were found

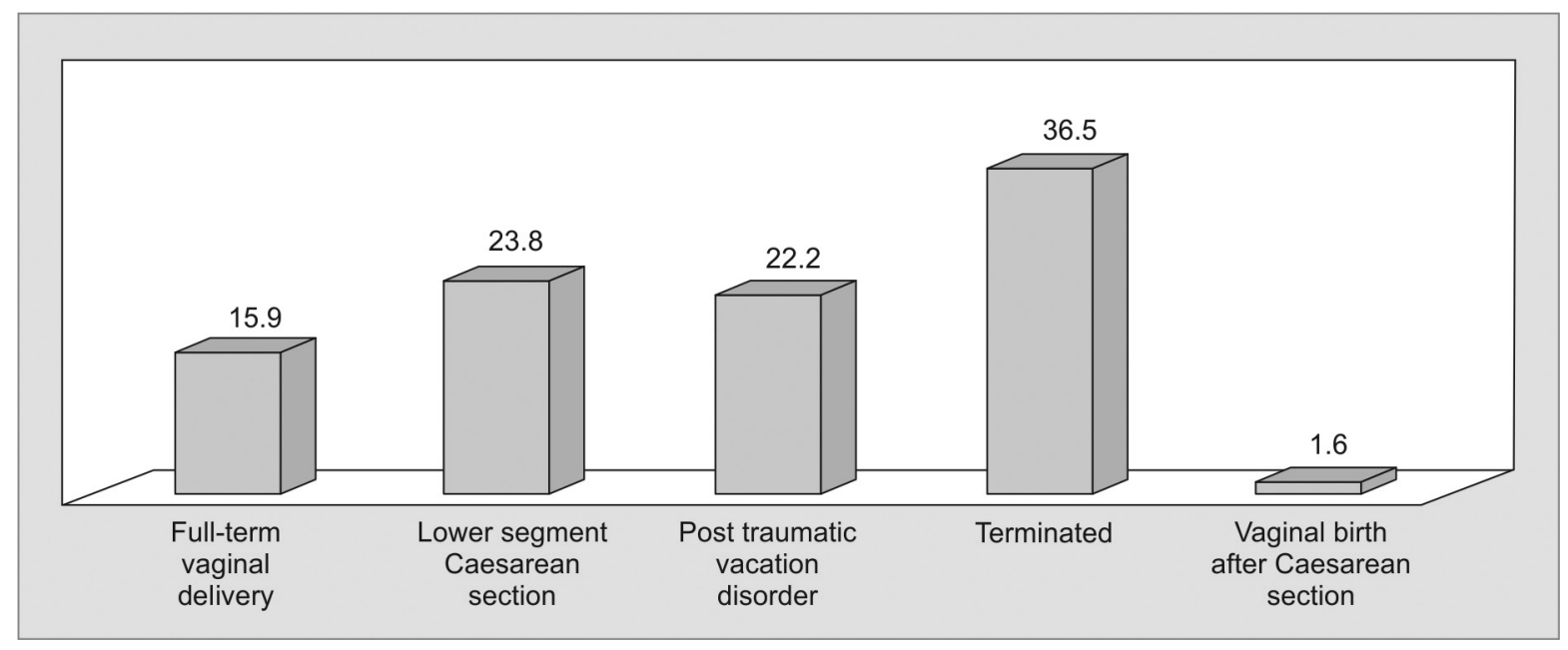

Fig. 10: Outcome of pregnancies with anomalies. 
to be lethal and $40 \%$ non-lethal (Table 6 and Fig 6). Consangunity was seen in $11.1 \%$. (Table 7 and Fig. 7). Booked cases $-17.5 \%$, booked outside $-49.2 \%$, unbooked $-33.3 \%$ (Table 8 and Fig 8).

Seventy-three percent of the mothers had no associated antenatal complications. Two mothers were diagnozed with TORCH (Table 9 and Fig 9). The outcome of pregnancies with anomalies were noted as termination by LSCS $23.8 \%$, preterm vaginal delivery was $22.2 \%$,full term vaginal delivery was $15.9 \%$ and $36.5 \%$ cases with anomalous fetus were terminated at $<20$ week (Table 10 and Fig. 10). $68.2 \%$ patients had an ultrasound $<20$ weeks, $35.4 \%$ between 20 to $24 \mathrm{w}$ and $25.85 \%$ had USG $>28$ weeks. Out of 63 cases, 42 had USG $<24 \mathrm{w}$ and in 11 cases who had an FADS, anomaly was missed. Of the missed anomalies 4 were found to be NTD, 3 cardiac. Others being intracranial anatomical malformations, hydrocephalus, polydactyl and cleft palate.

\section{CONCLUSION}

Prevalence of anomalies was found to be $0.5 \%$ over 2 years in our hospital which is comparatively lower than the national average of 2 to $3 \%$ and it was $1.2 \%$ in a study conducted over 5 years (January 2008-December 2012) in the same hospital settings. The present study gave us an idea regarding the incidence of congenital anomalies and also its relation with associated maternal and fetal factors.

Timely antenatal diagnosis of malformations before 20 weeks of pregnancy will provide an opportunity to consult, counsel, intervene and reduce the high morbidity and mortality. More stress should be laid on prevention by providing preconception counselling and folic acid, regular antenatal care and antenatal diagnosis. Ultrasonographic screening for fetal anomaly requires a specialist in fetal medicine or a trained sonologist help to minimising missing anomalies. Genetic counselling and prenatal diagnostic tests should be made available to improve the outcome and survival. Early detection of anomalies can indicate for termination and reduce the high morbidity and mortality.

\section{REFERENCES}

1. Birth Defects Research. Centers for Disease Control and Prevention.

2. Bhat BV, Ravikumara M. Perinatal mortality in India-Need for introspection. Indian J Matern Child Health. 1996 JanMarch;7(1):31-33.

3. Abel EL. "Paternal contribution to fetal alcohol syndrome". Addiction Biology .2004 June 9;(2):127-133.

4. Agarwal SS, Singh U, Singh PS, Singh SS, Das V, Sharma A, et al. Prevalence and spectrum of congenital malformations in a prospective study at a teaching hospital. Indian J Med Res. 1991Dec;94:413-419

5. De Santis M, Cesari E, Cavaliere A, Ligato MS, Nobili E, Visconti D et al. "Paternal exposure and counselling: Experience of a Teratology Information Service". Reproductive Toxicology. 2008 Sep 1;26(1):42-46.

6. Sartorius GA, Nieschlag E. "Paternal age and reproduction". Human Reproduction Update 202010 Jan-Feb;16(1): 65-79.

7. Anderson, Diana, Schmid, Thomas E, Baumgartner, Adolf. "Male-mediated developmental toxicity". Asian Journal of Andrology 2014 Jan-Feb;16(1):81-88.

8. PS A, Thottumkal VA, Deepak MG. Congenital Anomalies: a Major Public Health Issue in India. International Journal of Pharmaceutical, Chemical \& Biological Sciences. 2013 Jul 1;3(3):577-585

9. "Birth Defects". Dec 15, 2015. Retrieved 17 Jan 2016.

10. Global, regional, and national age-sex specific all-cause and cause-specific mortality for 240 causes of death, 1990-2013: a systematic analysis for the Global Burden of Disease Study 2013. The Lancet [Internet]. Elsevier BV; 2015 Jan;385(9963):117-71.

11. Karbasi SA, Golestan M, Fallah R, Mirnaseri F, Barkhordari K, Bafghee S. Prevalence of Congenital Malformations in Yazd(Iran). ActaMedicaIranica. 2009 Sept; 47(2): 149153.

12. Sawardekar KP. Profile of major congenital malformations at Nizwa hospital 10-year review.J Paediatric Child Health. 2005 Jul;41(7):323-330. 